\title{
Upper Extremity Amputations and Prosthetics
}

\author{
Steven A. Ovadia, MD ${ }^{1}$ Morad Askari, MD ${ }^{1}$ \\ ${ }^{1}$ Division of Plastic, Aesthetic and Reconstructive Surgery, DeWitt- \\ Daughtry Family Department of Surgery, University of Miami, \\ Leonard Miller School of Medicine, Miami, Florida \\ Semin Plast Surg 2015;29:55-61.
}

\begin{abstract}
Address for correspondence Morad Askari, MD, DeWitt-Daughtry Family Department of Surgery, University of Miami, Leonard M. Miller School of Medicine, Clinical Research Building (CRB), 1120 NW 14th Street, Room 410, Miami, FL 33136

(e-mail: MAskari@med.miami.edu).
\end{abstract}

\author{
Abstract \\ Keywords \\ - amputation \\ - upper extremity \\ - arm \\ - finger \\ - hand \\ - prosthetic
}

Upper extremity amputations are most frequently indicated by severe traumatic injuries. The location of the injury will determine the level of amputation. Preservation of extremity length is often a goal. The amputation site will have important implications on the functional status of the patient and options for prosthetic reconstruction. Advances in amputation techniques and prosthetic reconstructions promote improved quality of life. In this article, the authors review the principles of upper extremity amputation, including techniques, amputation sites, and prosthetic reconstructions.
Amputations to the upper extremity may be performed as distal as the fingertip and as proximal as including the shoulder. Traumatic injuries and malignancies are the most frequent pathologies to necessitate amputation. ${ }^{1,2}$ With the advent of microsurgical techniques in the mid-20th century, limb-sparing management has become the preferred treatment for traumatic injuries and malignancies. Nevertheless, prolonged ischemic time following traumatic injury, as well as injuries compromising the vascular supply beyond repair will preclude limb-sparing approaches. ${ }^{3}$ Regarding malignancies, recurrent tumors and uncontrollable pain are among a small handful of indications for amputation. ${ }^{4-6}$

The general principles of upper extremity amputation will be common to amputation at any level. In all amputations, the goal is to remove a distal segment of the extremity. This will entail dividing all structures spanning from the proximal limb to the distal segment being amputated. Structures including arteries, veins, nerves, tendons, ligaments, and bones will be divided. Following amputation of the limb, soft tissue coverage will be necessary either through local flaps prepared at the start of the case or other means, including skin grafting or free tissue transfer. ${ }^{1,7}$

\section{Operative Techniques and Considerations}

\section{Tourniquet Use}

A tourniquet can be useful to reduce blood loss and facilitate identification of anatomical structures. However, a tourni- quet is avoided when the indication for amputation is infection or malignancy. ${ }^{7,8}$ As in any other procedure in the upper extremity necessitating the use of a tourniquet, duration of ischemia time must be monitored as prolonged application of tourniquet can result in reperfusion injury. Two-hour use is commonly considered the time limit for tourniquet use in upper extremity procedures. If additional tourniquet use is necessary, it can be reinflated after 5 minutes for each 30 minutes of ischemia. ${ }^{9,10}$

\section{Neuroma Prevention}

With the division of nerves comes a risk for the development of symptomatic neuromas. When a nerve is cut, the proximal end will exhibit axonal sprouting. This phenomenon potentially allows the proximal end to reconnect with the distal end. However, when the distal end is lost as with an amputation, the severed nerve end may instead form a neuroma. ${ }^{11}$ This formation of a neuroma in itself is a benign process. However, it can become a painful problem when the neuroma is located in scar tissue or an area of frequent contact or high pressure, such as a limb stump.

Various surgical techniques can be employed during the initial amputation for prevention of symptomatic neuromas or after amputation for treatment of painful neuromas. Traction neurectomy is a commonly employed technique in which tension is applied to the nerve prior to division (-Fig. 1). This results in proximal retraction of the nerve away from the
Issue Theme Complex Upper Extremity Reconstruction; Guest Editors, Morad Askari, MD, and Steven L. Moran, MD
Copyright $\odot 2015$ by Thieme Medical Publishers, Inc., 333 Seventh Avenue, New York, NY 10001, USA. Tel: +1(212) 584-4662.
DOI http://dx.doi.org/ 10.1055/s-0035-1544171. ISSN 1535-2188. 

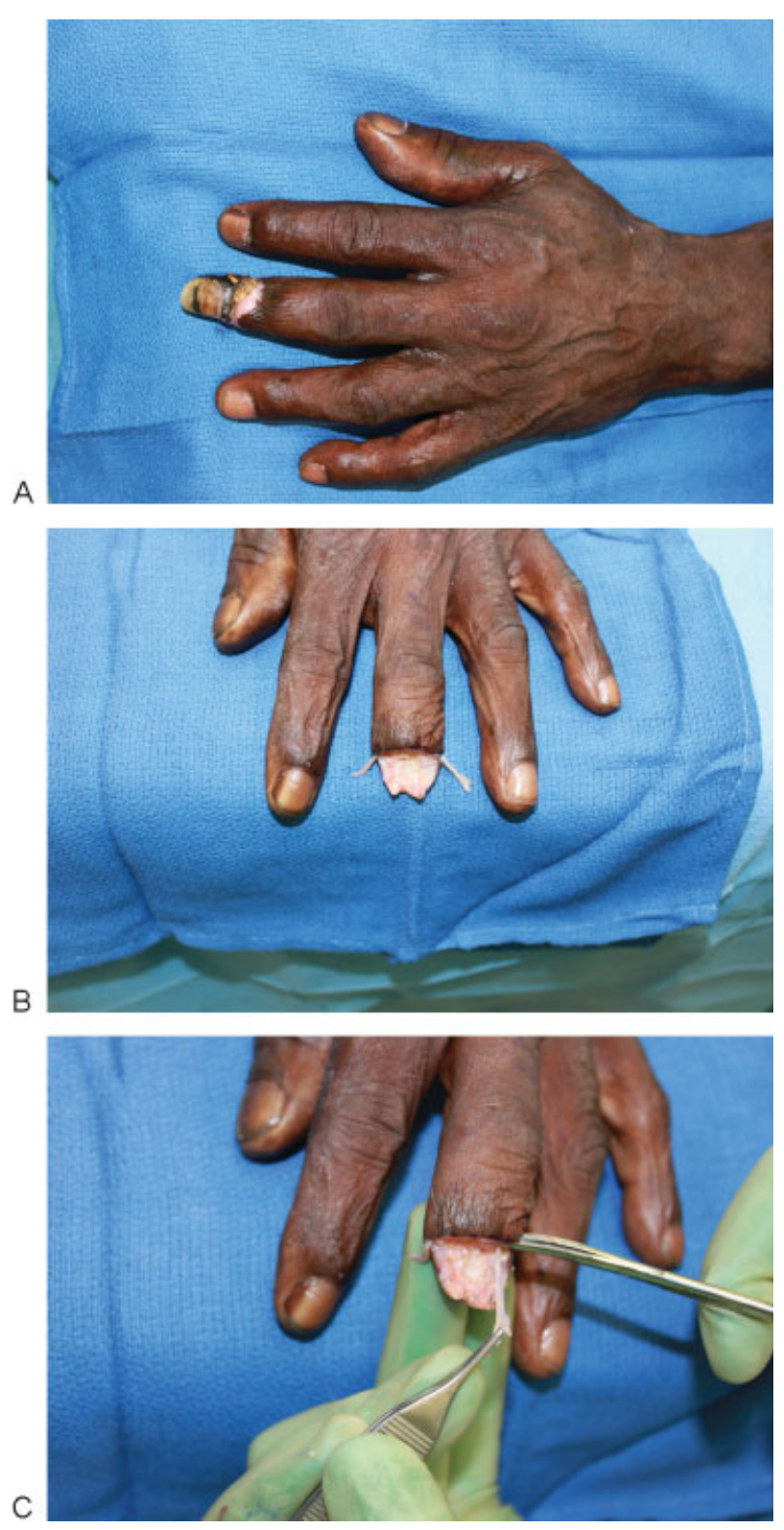

Fig. 1 (A) Distal long finger to be amputated due to distal necrosis and osteomyelitis. (B) Digital nerves are carefully dissected prior to division. (C) Traction is applied to digital nerves during division to locate neuroma away from stump site.

distal sites that will be subject to substantial pressure with prosthetic use. ${ }^{12}$ An alternative procedure entails burying the severed nerve into nearby muscle or bone. ${ }^{13}$ Centrocentral nerve union in which two severed nerves are coapted to form a loop has also been reported with success. ${ }^{14}$ Targeted muscle reinnervation, a procedure utilized to prepare the stump for myoelectrically controlled prosthetics may also have the additional benefit of preventing painful neuromas. ${ }^{15}$ Similarly, silicone capping of the proximal nerve end has also been described as a strategy to prevent symptomatic neuroma. ${ }^{12,16}$ However, the placement of these caps comes with the risk of an adverse reaction to the silicone. As this technique has only been studied in a limited number of small studies, the true extent and incidence of adverse effects are not known. Never- theless, other uses of in vivo silicone have been found to cause infection, granuloma formation, and migration. ${ }^{17,18}$

\section{Disarticulation}

The small joints of the hand in coordination with the wrist, elbow, and shoulder joint provide for the precise dexterity of the upper extremity. In planning an amputation, preservation of this dexterity is directly dependent on the number of functional joints that are maintained in the stump. Each joint also represents a potential site for amputation through disarticulation. The premise of disarticulation is similar to that of any amputation: separate proximal from distal structures to allow removal of the distal segment. However, because the joint inherently contains a discontinuity in bone, a disarticulation is distinguished in that bone does not need to be transected. Instead, a disarticulation divides the extremity by dissecting apart all soft tissue connections stabilizing the joint. Disarticulation is preferred when it allows for greater bone length or protection of tendinous insertions. ${ }^{1,7}$ One aspect of the disarticulation procedure that remains contentious is whether the articular cartilage should be preserved or removed. Leaving the cartilage in place has been speculated to promote infection. ${ }^{19}$ However, preserving the cartilage also offers several potential benefits, including maintaining a closed marrow cavity and preventing adherence of skin directly to bone. ${ }^{20,21}$ Despite these proposed risks and benefits, the true implications of preserving articular cartilage has not been well studied. Without convincing evidence, no consensus has been reached as evidenced by a 2013 survey of 592 hand surgeons. Results from the survey indicated $57 \%$ of surgeons remove articular cartilage in digital disarticulations with the remaining surgeons leaving the cartilage in place. ${ }^{22}$

\section{Osteotomy}

In addition to amputation by disarticulation, osteotomy with transection of the bone is an alternate means of amputation. Whereas disarticulation allows amputation at joints, osteotomy allows amputation at all other positions. From a practical standpoint, the different sites for transection include transphalangeal, transmetacarpal, transcarpal, transradial, and transhumeral. ${ }^{1,7,23}$

\section{Osteoplasty}

Prior to soft tissue closure, it is important to ensure that a smooth contour to the underlying bone has been achieved. Contouring any edges or uneven areas on the underlying bone can prevent potentially painful pressure points. ${ }^{7,24}$ This is of particular importance in allowing patients to wear prosthetics that exert constant pressure on the amputation stump.

Rasping is useful in smoothing the end of the transected bone. Additionally, natural surface irregularities or prominences, such as the radial and ulnar styloid processes, could be transected or rasped to more rounded surfaces to prevent undesirable pressure points. $^{7}$

\section{Myodesis and Myoplasty}

Adequate padding at the amputation site is another important consideration to prevent pain at the amputation stump. 
The myodesis and myoplasty techniques offer a means of increasing soft tissue padding at the amputation site. Myodesis entails suturing the muscle directly to the bone. In contrast, myoplasty entails suturing muscles together, typically agonist-antagonist pairs such as flexors and extensors. Anterior and posterior muscles are sutured such that the conjoined muscles cover over and pad the amputation stump. $2,7,24$

Myoplasty when performed alone places patients at risk for complications. Due to absence of a bony fixation point, a painful bursa may also develop between the muscle and the bone. Additionally, the unaffixed muscles have undesired mobility that can damage surrounding tissue. ${ }^{23,25}$ In general, this technique should be avoided in the digits as it compromises motion proximal to the amputation site. ${ }^{7,26,27}$ Myodesis, though technically more challenging, avoids these undesired complications while potentially allowing for activation of myoelectric prosthesis. ${ }^{22,25,28}$

\section{Soft Tissue Coverage}

Although soft tissue coverage is the final step of amputation, it should be planned at the start of the procedure. Local tissue flaps are ideal when significant soft tissue is available. However, when the extent of soft tissue loss is greater due to trauma or resection of malignancy, other reconstructive options should be used to maintain as much length as possible following amputation. Skin grafting can be performed when the amputation site has adequate coverage with muscle or subcutaneous tissues. Alternatively, options for local and distant surgical flaps, followed by free tissue transfer may be considered to ensure appropriate soft tissue at the amputation site. When reconstruction is not feasible, a more proximal amputation is attempted as a last resort to allow for adequate soft tissue coverage of bone.

\section{Level-Specific Principles}

\section{Digital Amputations}

\section{Thumb}

With digital amputations, the location of the amputation and involved finger is important. Thumb amputations can be the most debilitating given the functional importance of the thumb in opposition and prehension. When amputation is necessary, efforts should focus on preservation of length, sensation, and mobility. ${ }^{7}$ The importance of length preservation is highlighted by the strong correlation between functional impairment and level of amputation. Patients receiving amputations in the thumb at or distal to the interphalangeal joint experience some loss of dexterity, but retain good overall function. ${ }^{7}$ In contrast, amputation through the proximal phalanx will impair opposition with subsequent decrease in pinch and grip strength. Amputations at and proximal to the metacarpophalangeal (MCP) joint will result in complete loss of the thumb's function. Nevertheless, length preservation remains important as more reconstructive options are available when all or most of the metacarpal remains intact. Reconstruction of more proximal amputations will be re- stricted to pollicization and toe transplantation, both of which entail donor-site morbidity. ${ }^{7,27,29}$ In contrast, metacarpal lengthening is an option when all or most of the metacarpal remains. This technique utilizes distraction osteogenesis to produce a longer, more functional stump. ${ }^{30} \mathrm{Good}$ results have been reported with this technique without additional donor-site morbidity. ${ }^{31,32}$ Deepening of the first web space to further increase the effective length of the remaining thumb has also been described. ${ }^{30}$

\section{Distal Digital Amputation}

In performing amputation at the level of the distal phalanx, when possible, the insertion of flexor and extensor tendon should be preserved while providing durable coverage to the stump ( - Fig. 2). Amputations at this level may result in nail horn formation. Care should be taken to ablate the entire nailbed, including the germinal matrix when greater than two-thirds of the nailbed is lost or removed. ${ }^{7}$ When the entire distal phalanx is removed, tendons are cut short and allowed to retract. Suturing flexor tendon to extensor tendon to cover the bony stump should be avoided as this maneuver can result in the "quadriga effect" with resultant loss of grip strength. ${ }^{7,26,27}$ Instead, a wide variety of local and cross finger flap options can be employed for soft tissue coverage to the digital stump. ${ }^{7}$

Patients are at risk for the development of a lumbrical plus deformity when amputations are performed at the distal interphalangeal joint. This deformity entails a paradoxical extension of the phalanges when the MCP joint is flexed. Amputation at the distal interphalangeal joint releases the flexor digitorum profundus (FDP) tendon from its insertion on the distal phalanx. The tendon subsequently retracts proximally and because the lumbrical originates on the FDP tendon, the body is of the lumbrical may be drawn proximally with the FDP contraction when flexion is attempted. If the lumbrical's insertion onto the extensor apparatus has been maintained, the increased tension from FDP contraction will cause the paradoxical phalangeal extension of the lumbrical plus deformity. ${ }^{33}$

\section{Proximal Digital and Ray Amputations}

Amputations along the proximal phalanx will be proximal to the insertion of the superficial flexors and therefore render the residual finger stump with poor flexion. The amputation may result in hindrance to hand function and grip strength. When affecting more central digits, it may result in a gap that will interfere with holding small objects in the palm. In such cases, a ray amputation may be more beneficial to the patient. ${ }^{7,27}$

Ray amputation entails removal of the entire digit as well as all or the greater part of the corresponding metacarpal (-Fig. 3). In this technique, the adjacent metacarpals are moved in place of the removed metacarpal by repairing the transverse metacarpal ligament to close the resulting gap. Ray amputation therefore results in narrowing of the hand that can decrease grip strength. This decrease in grip strength has to be weighed against the gain the patient may experience from a more functional grip and will vary with the specific finger involved. ${ }^{34,35}$ 

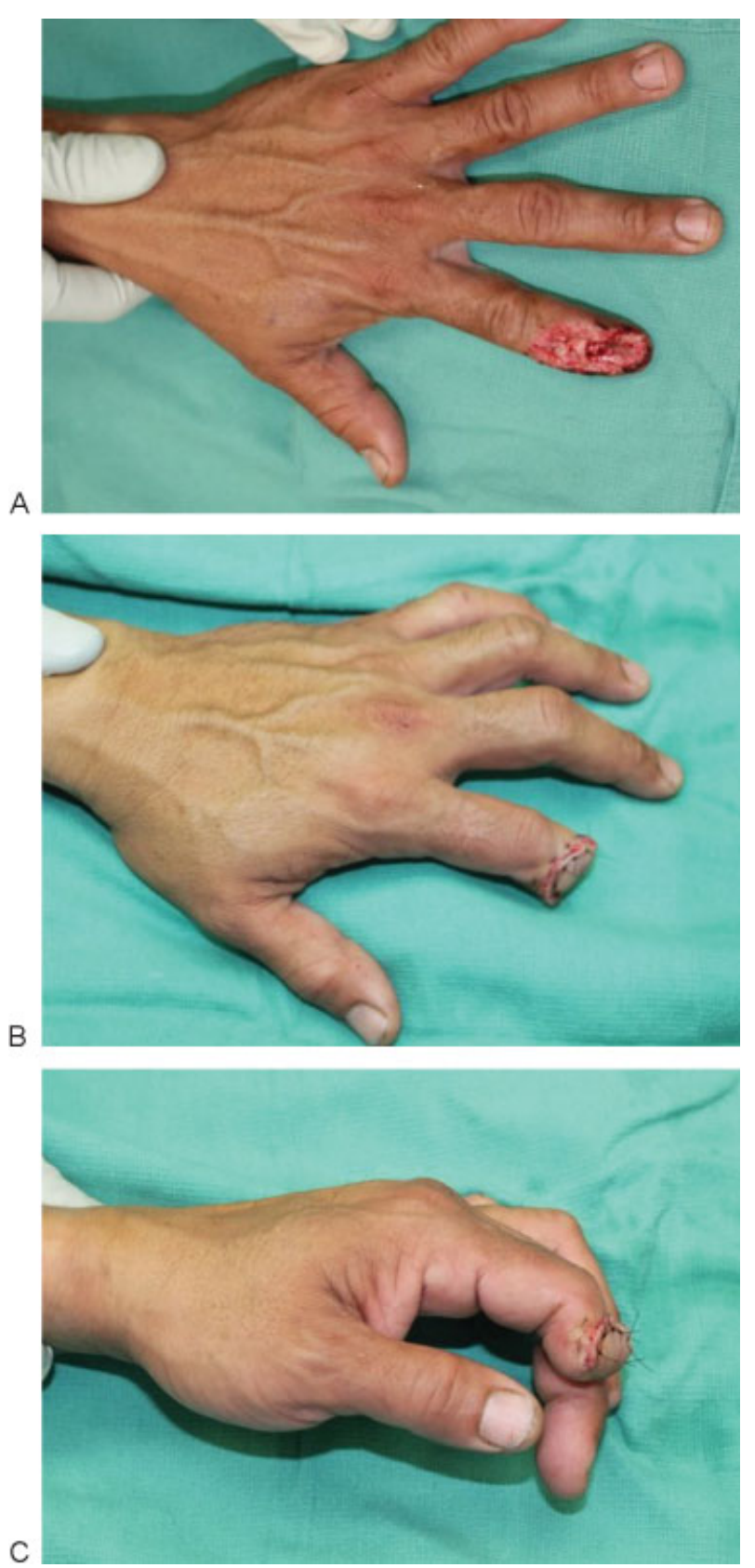

Fig. 2 (A) Crush injury to index finger necessitating partial amputation of distal phalanx. (B) Soft tissue closure is achieved with a local skin flap. (C) Proximal interphalangeal joint flexion is preserved by maintaining the insertion site of the flexor digitorum superficialis.

Ray amputation of the index finger may be appropriate when alternative options would leave only a small stump. The index finger functionally enables a pinching action in conjunction with the thumb. However, if the remnant stump is too short, this role will be transferred to the middle finger. A remnant stump may impede this transition thereby making ray amputation preferable. ${ }^{7,27}$ Ray amputation of the middle and ring finger may also provide for a more functional hand than a small remnant stump. Substantial length of these digits is necessary to prevent grasped items from falling through the gap. When this problem occurs, ray amputation may be preferable as it would eliminate this gap. Lastly, ray amputation

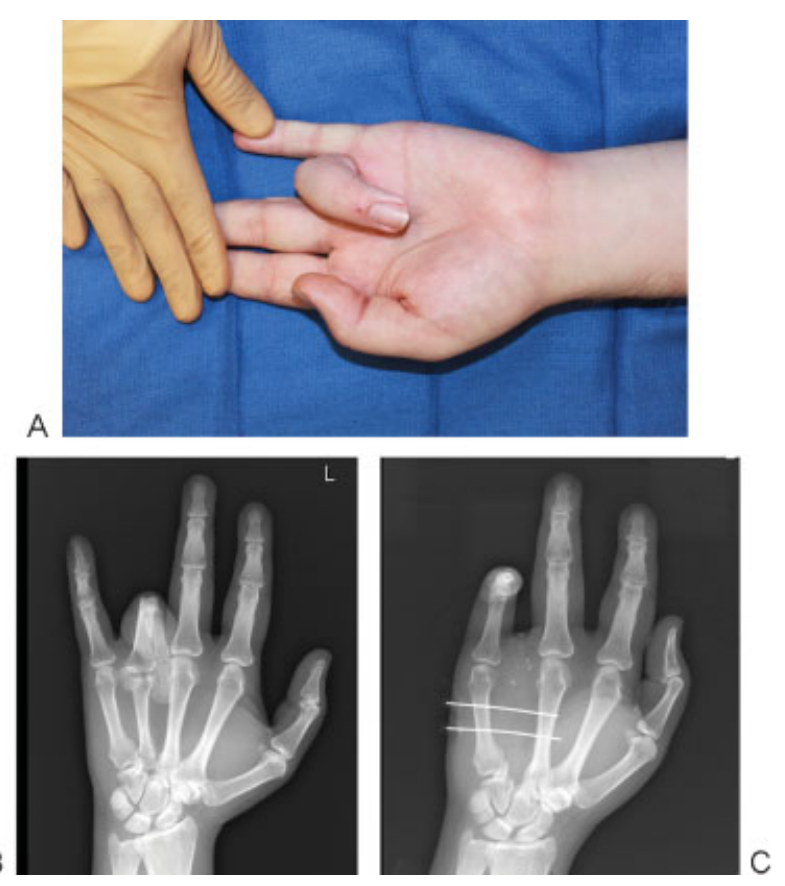

Fig. 3 (A) Contracted insensate ring finger to be removed by ray amputation. (B) Radiograph demonstrating severe contraction deformity. (C) Radiograph after ring finger ray amputation. The third and fifth metacarpals were temporarily secured with K-wires to prevent widening of the web space during healing.

of the little finger mostly offers a cosmetic benefit that must be weighed against the potential loss of grip strength. ${ }^{7,27}$

\section{Proximal Amputations}

Preservation of length is an important goal in proximal upper extremity amputations. Because torque is equal to force applied multiplied by distance from the fulcrum $(\tau=F \times d)$, a longer-lever arm allows for generation of greater torque. This improves the functional utility of a prosthesis. The longer-lever arm also allows for the generation of a given amount of torque with a smaller force, in turn placing less pressure on the soft tissue.

The elbow and wrist disarticulation procedures are useful in preserving length when the alternative would be amputation proximal to the joint. Furthermore, in preserving the joint, these procedures offer additional benefits. Elbow disarticulation maintains a patient's ability to rotate the humerus. $^{7}$ This motion can provide an additional means of control to a prosthetic device. Additionally, the preservation of the humeral condyles provides a good foundation onto which prosthetic devices can be fitted. 2,7,36

Wrist disarticulation similarly maintains additional range of motion compared with amputation through the radius and ulna. By preserving the distal ulnar radial joint, the ability to pronate and supinate the forearm is maintained. Shoulder disarticulation does not offer the same functional benefits as wrist and elbow disarticulation. Disarticulation at the shoulder entails removing the entire extremity. Nevertheless, the procedure is less disfiguring than the more proximal forequarter amputation. ${ }^{2,7}$ 
When disarticulation will not adequately treat a patient, it is appropriate to amputate by osteotomy of the underlying bones. The same general principles of amputation will apply at these levels as well as the importance of maintaining length. Below elbow amputations benefit from increased length because it improves retention of pronation and supination of the arm. Although proximal forearm amputations will lose forearm pronation and supination, elbow flexion will be retained, provided at least $4 \mathrm{~cm}$ of ulna is maintained. ${ }^{7}$

In above-elbow amputations, shoulder movement is generally preserved. More proximal amputations in the arm may result in complete loss of shoulder movement. However, preservation of length is still an important goal as it will improve the contour of the shoulder. ${ }^{7}$ At times, it may be necessary to amputate the upper extremity proximal to the shoulder joint. The more radical, more proximal amputation known as the forequarter amputation is generally reserved for patients with severe malignancies involving the shoulder., ${ }^{4,37}$

The forequarter amputation entails removing the arm, clavicle, and scapula and is therefore highly disfiguring. The procedure results in a loss of shoulder contour that is cosmetically undesirable and impairs the patient's ability to properly fit clothing. ${ }^{38}$ Prosthetic options are also the most limited and least functional. ${ }^{39}$ Nevertheless, when appropriate the procedure may improve quality of life and can be lifesaving. ${ }^{40}$

\section{Prosthetics}

\section{Suspension}

One important element of successful prosthetics is good suspension to the body. Several strategies have been utilized for this purpose, including self-suspended sockets, suction sockets, and harness suspension. ${ }^{2,36}$ Many factors will contribute to the suitability of a particular suspension strategy. Because some of these factors can be altered during the amputation, prosthetic considerations should factor into the operative planning.

Self-suspended sockets are designed to match the shape of the amputation stump. This suspension holds the prosthetic in place by gripping around the prosthetic. ${ }^{2}$ A flare at the end of the bone improves this grip, a factor that should be considered during the operation. The radial styloid process is an example of a bony flare that can improve suspension after wrist disarticulation. For this reason, though this bone should still be rasped to round its surface, it should not be resected. $^{7}$

The suction sockets rely on a one-way valve to generate a vacuum between the prosthetic and the limb stump. This in turn will create a seal to hold the two together. Suction sockets will thereby require a smooth skin surface free of invaginations or depressed scars. ${ }^{2,36}$

Harness-based suspensions are a very versatile option for patients. They can be used as primary means of suspension or in conjunction with self-suspended and suction sockets. Harness-based suspensions hold the prosthetic in place by tethering it to the trunk. This allows the use of harness-based suspension when the requirements for other suspensions cannot be met. ${ }^{2,36}$

\section{Types of Prosthetics}

The goal of a prosthetic is to restore the form and function of the lost extremity. Several classes of prosthetics have been developed to achieve these goals. Major classes include passive, body powered, and externally powered. Passive prosthetics, also referred to as cosmetic prosthetics, primarily focus on achieving a naturally appearing extremity. The improved cosmesis comes with the cost of reduced functionality. These prosthetics are limited to basic tasks such as pushing and pulling, as well as stabilizing a held object. ${ }^{2,36}$

Body-powered prosthetics make use of cables, pulleys, and hooks to increase the functionality of the prosthesis. These prosthetics are harnessed to a patient and are activated by the remaining motility of the limb stump. When amputation has left a patient without a functioning elbow, a body-powered prosthetic can allow for elbow-like flexion and extension at the limb stump-prosthetic junction. Alternatively, a prosthetic can be fitted with a distal hook designed to open or close upon motion of the limb stump. Although a traditional bodypowered prosthetic is powered by the patient's own movements, externally powered, motorized versions can augment the actions of these devices. ${ }^{2,23,36}$

Externally powered prosthetics also include the highly functional, myoelectrically controlled devices. The motor functions of these devices are initiated by a patient's own muscles. The volitional decision to contract a muscle causes a nerve to stimulate a muscle and subsequently depolarize that muscle. This depolarization of muscle leads to electromyographic (EMG) signals that can be detected by the prosthesis. Each muscle at the stump site provides a unique signal that can trigger a specific action within the prosthetic device. Actions including flexion, rotation, opening, and closing can be achieved with the use of these signals. The number and variety of actions achievable with the prosthesis will be limited by the number of suitable muscles at the stump site. However, to increase functionality, these devices can be designed to have multiple modes. A single muscle can thereby enable multiple actions, such as flexion and rotation. To toggle between modes, the patient sends a specific signal to the device. Co-contraction of two muscles is a commonly employed signal for the device to switch modes. ${ }^{2,23,36}$

Targeted muscle reinnervation (TMR) has been used to enhance a patient's experience using a myoelectric prosthetic device. Traditionally, myoelectric prostheses rely on linking the contraction of a specific muscle with a specific prosthetic action. However, the specific muscle and action may have no physiologic relationship making prosthetic use less intuitive for the operator. Targeted muscle reinnervation is an invasive procedure intended to make prosthetic use more intuitive. Targeted muscle reinnervation entails coapting nerves that would otherwise be amputated with the motor nerves of muscles remaining at the stump site. For example, the pectoralis major muscle can be "reinnervated" with the median nerve. The prosthetic device can be designed to pick up the EMG signals at the pectoralis major muscle and trigger a hand prosthesis to close. Because the median nerve innervates hand flexors, pairing it with closing the prosthetic hand provides a more intuitive experience. ${ }^{7,41,42}$ 
Additionally, target muscle reinnervation can also increase the number of distinct EMG signals detectable by the prosthesis. This further enhances control of the prosthesis by allowing for additional motions that can be initiated simultaneously. ${ }^{43}$

\section{Conclusion}

Upper extremity amputations are devastating and will profoundly impact the life of the affected patient. A successful amputation and reconstruction can decrease the extent of the loss. Surgical goals include removing the damaged or diseased limb, minimizing long-term complications, and preparing a limb stump that can be fitted for a prosthetic. Following surgery begins the long rehabilitation process in which the most comfortable and functional prosthetic is determined for the individual. With advancing technology, new prosthetic options will continue to be developed, thus helping to ameliorate the substantial loss associated with an upper extremity amputation.

\section{References}

1 Cioffi WG. Upper extremity amputations. In: Cioffi WG, Asenio JA, eds. Atlas of Trauma: Emergency Surgical Techniques. Philadelphia, PA: Elsevier/Saunders; 2014:297-320

2 Cuccurullo S. Physical Medicine and Rehabilitation Board Review. New York, NY: Demos Medical; 2004

3 Prucz RB, Friedrich JB. Upper extremity replantation: current concepts. Plast Reconstr Surg 2014;133(2):333-342

4 Levine EA, Warso MA, McCoy DM, Das Gupta TK. Forequarter amputation for soft tissue tumors. Am Surg 1994;60(5):367-370

5 Luna-Ortiz K, Maafs-Molina E, Herrera-Gómez A, Barrera-Franco JL. Is there an indication for palliative surgical procedure of shoulder and upper limb malignancies? Cir Cir 2003;71(2):102-106

6 Nierlich P, Funovics P, Dominkus M, Aszmann O, Frey M, Klepetko W. Forequarter amputation combined with chest wall resection: a single-center experience. Ann Thorac Surg 2011;91(6):1702-1708

7 Green DP, Wolfe SW. Green's Operative Hand Surgery. Philadelphia, PA: Elsevier/Churchill Livingstone; 2011

8 Bowker JH. Elbow disarticulation and transhumeral amputation. In: Bowker JH, Michael JW, eds. Atlas of Limb Prosthetics: Surgical, Prosthetic, and Rehabilitation Principles. St. Louis, MO: Mosby Year Book; 1992:251-264

9 Heppenstall RB, Balderston R, Goodwin C. Pathophysiologic effects distal to a tourniquet in the dog. J Trauma 1979;19(4):234-238

10 Tountas CP, Bergman RA. Tourniquet ischemia: ultrastructural and histochemical observations of ischemic human muscle and of monkey muscle and nerve. J Hand Surg Am 1977;2(1):31-37

11 Rowland LP, Pedley TA, Houston Merritt H. Pathophysiology of neuropathic pain. In: Rowland LP, Pedley TA, eds. Merritt's Neurology. $12^{\text {th }}$ ed. Philadelphia, PA: Lippincott Williams \& Wilkins; 2010:839-840

12 Tupper JW, Booth DM. Treatment of painful neuromas of sensory nerves in the hand: a comparison of traditional and newer methods. J Hand Surg Am 1976;1(2):144-151

13 Dellon AL, Mackinnon SE. Treatment of the painful neuroma by neuroma resection and muscle implantation. Plast Reconstr Surg 1986;77(3):427-438

14 Gorkisch K, Boese-Landgraf J, Vaubel E. Treatment and prevention of amputation neuromas in hand surgery. Plast Reconstr Surg 1984;73(2):293-299

15 Kim PS, Ko JH, O'Shaughnessy KK, Kuiken TA, Pohlmeyer EA, Dumanian GA. The effects of targeted muscle reinnervation on neuromas in a rabbit rectus abdominis flap model. J Hand Surg Am 2012;37(8):1609-1616

16 Swanson AB, Boeve NR, Lumsden RM. The prevention and treatment of amputation neuromata by silicone capping. J Hand Surg Am 1977;2(1):70-78

17 Morrison AD, Sanderson RC, Moos KF. The use of silastic as an orbital implant for reconstruction of orbital wall defects: review of 311 cases treated over 20 years. J Oral Maxillofac Surg 1995;53(4): 412-417

18 Rapaport MJ, Vinnik C, Zarem H. Injectable silicone: cause of facial nodules, cellulitis, ulceration, and migration. Aesthetic Plast Surg 1996;20(3):267-276

19 Rank BK, Wakefield AR, Hueston JT. Surgery of Repair as Applied to Hand Injuries. 3rd ed. Edinburgh and London, UK: E \& S Livingstone; 1968

20 Graham WP, Kilgore ES, Whitaker LA. Transarticular digital joint amputations: preservation of the articular cartilage. Hand 1973; 5(1):58-62

21 Graham WP III, Pataky PE, Whitaker LA, et al. Transarticular joint amputations: the value of preserving articular cartilage. J Surg Res 1973;14(6):524-537

22 Li A, Meunier M, Rennekampff HO, Tenenhaus M. Surgical amputation of the digit: an investigation into the technical variations among hand surgeons. Eplasty 2013;13:e12

23 Musicus M, Davis AJ. Upper extremity prosthetic design and function. In: Spires MC, Kelly BM, Davis AJ, eds. Prosthetic Restoration and Rehabilitation of the Upper and Lower Extremity. New York, NY: Demos Medical Publishing; 2013:167-178

24 Bowker JH. Wrist disarticulation and transradial amputation. In: Bowker JH, Michael JW, eds. Atlas of Limb Prosthetics: Surgical, Prosthetic, and Rehabilitation Principles. St. Louis, MO: Mosby Year Book; 1992:237-250

25 Tintle SM, Baechler MF, Nanos GP III, Forsberg JA, Potter BK. Traumatic and trauma-related amputations: Part II: Upper extremity and future directions. J Bone Joint Surg Am 2010;92(18):2934-2945

26 Schreuders TA. The quadriga phenomenon: a review and clinical relevance. J Hand Surg Eur Vol 2012;37(6):513-522

27 Bowker JH. Partial-hand amputations. In: Bowker JH, Michael JW eds. Atlas of Limb Prosthetics: Surgical, Prosthetic, and Rehabilitation Principles. St. Louis, MO: Mosby Year Book; 1992:199-236

28 O'Shaughnessy KD, Dumanian GA, Lipschutz RD, Miller LA, Stubblefield $\mathrm{K}$, Kuiken TA. Targeted reinnervation to improve prosthesis control in transhumeral amputees. A report of three cases. J Bone Joint Surg Am 2008;90(2):393-400

29 Loda G. Thumb reconstruction. In: Atlas of Thumb and Finger Reconstruction. Stuttgart: Thieme; 1999:79-114

30 Cobb TK, Stocks GW, May WF, Strauss MR, Lewis RC Jr. Thumb reconstruction by metacarpal lengthening after traumatic loss at the level of the interphalangeal joint. Orthop Rev 1990;19(1):47-51

31 Finsen V, Russwurm $\mathrm{H}$. Metacarpal lengthening after traumatic amputation of the thumb. J Bone Joint Surg Br 1996;78(1):133-136

32 Matev I. Thumb metacarpal lengthening. Tech Hand Up Extrem Surg 2003;7(4):157-163

33 Parkes A. The "lumbrical plus" finger. J Bone Joint Surg Br 1971; 53(2):236-239

34 Melikyan EY, Beg MS, Woodbridge S, Burke FD. The functional results of ray amputation. Hand Surg 2003;8(1):47-51

35 Peimer CA, Wheeler DR, Barrett A, Goldschmidt PG. Hand function following single ray amputation. J Hand Surg Am 1999;24(6): 1245-1248

36 DeLisa JA, Gans BM, Walsh NE. Upper and lower extremity prosthetics. In: DeLisa JA, Gans BM, Bockenek WL, et al, eds. Physical Medicine and Rehabilitation: Principles and Practice. Philadelphia, PA: Lippincott Williams \& Wilkins; 2004:1325-1354

37 Koulaxouzidis G, Simunovic F, Stark GB. Shoulder silhouette and axilla reconstruction with free composite elbow tissue transfer following interscapulothoracic amputation. J Plast Reconstr Aesthet Surg 2014;67(1):81-86 
38 Pasquina PF, Cooper RA. General Surgical Principles for the Combat Casualty with Limb Loss. Care of the Combat Amputee. Falls Church, VA: Office of the Surgeon General, United States Army; 2009

39 Murphy D. Shoulder disarticulation and forequarter amputation. In: Fundamentals of Amputation Care and Prosthetics. New York, NY: Demos Medical; 2014:177-188

40 Eralp L, Özger H, Eren I, Dikici F. Forequarter amputation as a lifesaving procedure. Musculoskelet Surg 2011;95(2):127-130
41 Thorne C. Grabb and Smith's Plastic Surgery. Philadelphia, PA: Wolters Kluwer Health/Lippincott Williams \& Wilkins; 2014

42 Kuiken TA, Dumanian GA, Lipschutz RD, Miller LA, Stubblefield KA. The use of targeted muscle reinnervation for improved myoelectric prosthesis control in a bilateral shoulder disarticulation amputee. Prosthet Orthot Int 2004;28(3):245-253

43 Kuiken T. Targeted reinnervation for improved prosthetic function. Phys Med Rehabil Clin N Am 2006;17(1):1-13 Review 